The results for Stages 4 and 5 demonstrate that a period STO alone could not support responding on the TO lever.

Although responding in the first $5 \mathrm{~min}$ of each avoidance period increased in Stage 2, there was no overall increase in the TO rate, and TO rates in the first halves of the avoidance periods were never as high as those in the second halves.

\section{DISCUSSION}

The typically scalloped FI performance obtained on the TO lever is similar to that obtained under appetitive reward. Neither Verhave (1962) nor Findley \& Ames (1965) found this in their investigations of FI schedules of production of TO from avoidance, but the patterns of FI responding that they found also differed from one another. The reasons for these discrepancies are not clear at present.

In Stage 2, typical FI responding was also maintained by STO when it was programmed on a second-order schedule. However, when STO was not associated with TO, in Stages 5 and 6, it could not maintain responding. This confirms that STO is a secondary reinforcer and that the absence of the avoidance contingency is the primary reinforcer.

The secondary reinforcement demonstrated in Stage 2 was quite weak and was not reflected in a higher overall $\mathrm{TO}$ response rate. This was probably because of the very good temporal discrimination shown, and is illustrated by the high quarter-lives. Nevertheless, this experiment demonstrates a technique whereby positive secondary reinforcement can be established in a situation using only negative primary reinforcement (electric shock).

Much attention has been focused on the conditions for the establishment of a stimulus as a secondary reinforcer. These are operationally similar to those involved in the classical conditioning paradigm (Kimble, 1961): There must be a conditional relationship between the stimulus and primary reward (secondary reinforcement) or unconditioned stimulus (classical conditioning). Temporal contiguity is only one of several relationships, or conditioning techniques, which are available (Pavlov, 1927). Similar ideas are embodied in the current hypotheses that a secondary reinforcer must be a discriminative stimulus (Keller \& Schoenfeld, 1950) or possess informational value (Miller, 1961).

The present results are compatible with the above formulations but it is the maintenance of secondary reinforcement which is emphasized. Secondary reinforcement was not established and then "tested" in a situation where it had no relevance to primary reward, e.g., Egger \& Miller (1963). That STO did not support responding when it was available on FI $5 \mathrm{~min}$ with a limited hold, although it did without the limited hold, suggests that the maintenance of secondary reinforcement requires that the production of primary reinforcement be conditional upon the production of the secondary reinforcer. The introduction of the limited hold means that STO can be "missed" and yet TO still remains available contingent on the first $\mathrm{TO}$ response $10 \mathrm{~min}$ after the start of the avoidance period. If STO is missed, the schedule becomes that of Stage 1; but if it maintains responding, then the schedule becomes equivalent to that of Stage 2. When there is no limited hold, the first TO response after $5 \mathrm{~min}$ must produce STO and a further $5 \mathrm{~min}$ must elapse before a TO period can possibly be produced, i.e., STO must be produced here.

If emphasis is placed on the conditional nature of secondary reinforcement and upon the maintenance of secondarily reinforced responding, and not upon the fact that approximate contiguity between a stimulus and primary reinforcement is an optimal method for establishing the stimulus as a secondary reinforcer (Bersh, 1951), it may be possible to explain the durability of secondary reinforcement outside the laboratory, which often seems paradoxical when compared with its apparent ephemeral nature under laboratory conditions (Razran, 1955). In everyday life, primary reward may be obtainable only if a secondary reinforcer is first procured; this conditional relationship may be maintained even though the primary and secondary reinforcers are not paired contiguously.

\section{REFERENCES}

BERSH, P. J. The influence of two variables upon the establishment of a secondary reinforcer for operant responses. Journal of Experimental Psychology, 1951, 41, 62-73.

EGGER, M.D., \& MILLER, N.E. When is a reward reinforcing? An experimental study of the information hypothesis. Journal of Comparative \& Physiological Psychology, 1963, 56, 132-137.

FINDLEY, J. D., \& AMES, L. L. A note on time out from avoidance with the chimpanzee. Journal of the Experimental Analysis of Behavior, 1965, 8, 419-423.

KELLEHER, R. T. Conditioned reinforcement in second-order schedules. Journal of the Experimental Analysis of Behavior, 1966, 9, 475-485.

KELLER, F. S., \& SCHOENFELD, W. N. Principles of psychology. New York: AppletonCentury-Crofts, 1950.

KIMBLE, G. A. Hilgard and Marquis' conditioning and learning. New York: Appleton-CenturyCrofts, 1961 .

MILLER, N. E. Analytic studies of drive and reward. American Psychologist, 1961, 16, 739-754.

PAVLOV, I. P. Conditioned reflexes. Translated by G. V. Anrep. London: Oxford University Press, 1927.

RAZRAN, G. A note on second-order conditioning and secondary reinforcement. Psychological Review, 1955, 62, 327-332.

SIDMAN, M. Two temporal parameters of the maintenance of avoidance behavior by the white rat. Journal of Comparative \& Physiological Psychology, 1953, 46, 253-261.

VERHAVE, T. The functional properties of a time out from an avoidance schedule. Journal of the Experimental Analysis of Behavior, 1962, 5, 391-422.

NOTE

1. This research was supported by a research studentship from the Science Research Council, U.K.

\title{
Task and species generality of the "helplessness" phenomenon
}

WILLIAM BRAUD, BARRY WEPMAN, and DANE RUSSO, University of Houston, Houston, Tex. 77004

Three groups ( $N=9$ ) of male albino mice were given six daily 2-h exposures to escapable, inescapable, or no electric shock. Shock was programmed on a 30-sec-on/30-sec-off alternating schedule. The pole-climbing behavior of an escapable shock $S$ could terminate or prevent shock both for itself and for its yoked inescapable shock pair-member. All Ss then were given, after a 24-h rest, five water-escape trials in which swimming time was measured. The escapable shock Ss learned the water-escape task faster than the no shock control Ss. The inescapable shock Ss swam increasingly slower over trials.
Seligman and his associates (Overmier \& Seligman, 1966; Seligman \& Maier, 1967) have reported that exposure of dogs to inescapable shocks under a variety of conditions reliably resulted in interference with subsequent escape-avoidance behavior in a new situation. Such proactive interference did not occur when, in the first task, shock termination was made response contingent. Seligman has rejected shock adaptation and competing skeletal response interpretations in favor of a "learned helplessness" hypothesis. According to this hypothesis, when shock termination is independent of responding, the S learns that the probability of shock termination in the presence of any given response does not differ from the probability of shock termination in the absence of that response; 
therefore, attempts to escape shock in other situations decrease in probability.

The purpose of the present study was to develop a simple and effective procedure which would facilitate further, more exhaustive, study of the parameters of the helplessness effect using small animals. A second purpose was to make a preliminary examination of the task and species generality of the effect.

\section{SUBJECTS}

The Ss were 27 male albino mice of the A strain, obtained from Texas Inbred Mice Co., Houston, Texas. The Ss were housed in groups of four, and were maintained on ad lib food and water throughout the experiment.

\section{APPARATUS}

The apparatus for shock training consisted of a pair of grid-floored, cylindrical, metal compartments, to be described in detail in a separate apparatus report. One of these chambers contained a vertical microswitched pole suspended from its top; the other chamber contained no pole. Scrambled shock applied to the grids of both chambers could be terminated or prevented by the pole-climbing behavior of the controlling member of the pair, i.e., the compartments were electrically yoked. Shock presentations were electronically programmed; pole climbs were recorded by ink-writing event markers.

Water-escape testing, the second task, was carried out in a metal tank, 40 in. long, 30 in. wide, and $18 \mathrm{in}$. deep, filled with tap water $(82 \operatorname{deg}$ F). A 3-in.-wide fiberboard escape ramp was provided at one end of the tank; this ramp area was illuminated by a flashlight beam in the otherwise darkened room.

\section{PROCEDURE}

The Ss were divided into three groups of nine animals each. The escapable shock Ss were given $2 \mathrm{~h}$ of shock training on each of 6 consecutive days. Throughout any 2-h period, $0.5 \mathrm{~mA}$ of scrambled ac was applied to the grid according to a 30-sec-on/30-sec-off alternating schedule. An $\mathrm{S}$ could escape this shock at any time by jumping onto the vertical pole. Thus, an $S$ could experience a minimum of no shock (perfect temporal avoidance) and a maximum of 60 min of shock per 2-h session (complete failure to escape or avoid).

The chamber of each escapable shock $S$ was electrically yoked to the poleless chamber of an inescapable shock $S$, so that the pole-climbing behavior of the controlling members terminated or prevented shock both for themselves and for their yoked pair members. Thus, the escapable and inescapable shock Ss received identical numbers, durations, and temporal

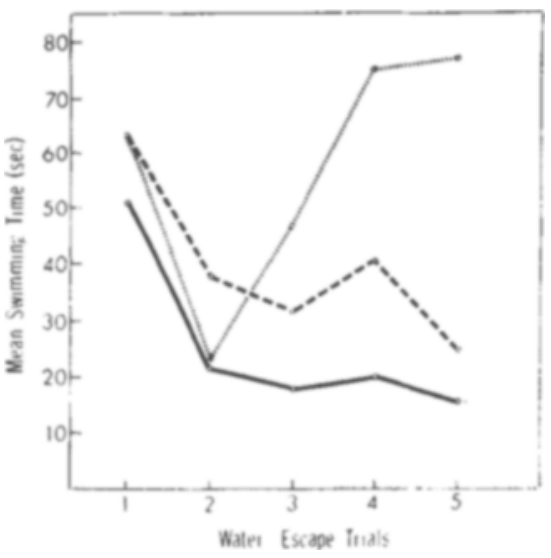

Fig. 1. Mean swimming time as a function of the five water-escape trials.

patterns of shock; in whatever manner, however, these shocks were controlled only by escapable shock Ss.

The Ss of the no shock control group were simply placed in the chambers for $2 \mathrm{~h}$ on each of 6 consecutive days; grids were never electrified for these Ss.

Following the 6 days of shock training, all Ss were given five water-escape test trials, with an intertrial interval of $1 \mathrm{~min}$. An $\mathrm{S}$ was placed in the water tank at the end opposite the ramp; E recorded S's time to swim to the ramp and escape the water. If the $S$ did not escape in $5 \mathrm{~min}$, it was removed and a score of $300 \mathrm{sec}$ was recorded for that trial. The $\mathrm{E}$ who ran the Ss through their water-escape trials was unaware of the $\mathrm{Ss}^{\prime}$ group membership.

\section{RESULTS}

The shock-escape response (pole climbing) was readily acquired by the escapable shock Ss. These Ss made their first escape response after an average of only 3.3 shock presentations (range: one to nine shocks), and experienced an average of $85 \mathrm{sec}$ of shock (range: $40-251 \mathrm{sec}$ ) before the first escape response. A criterion of five consecutive escape responses with latencies of less than $5 \mathrm{sec}$ was always reached after an average of 5.5 shock presentations (range: three to nine shocks).

The water-escape performance of the three groups appears in Fig. 1 as a function of the five test trials. Both the control group (no shock) and the escapable shock group exhibit typical learning curves of decreasing escape times, with the escapable shock group consistently swimming faster than the no shock controls. On the other hand, the yoked inescapable shock group exhibits a dramatic increase in swimming time. An a priori determined statistical comparison of escape performance on the final test trial indicated that the two shock groups differed reliably ( $\mathrm{p}<.05$, Duncan's range test).

\section{DISCUSSION}

The present results indicate that an organism's degree of control of stressful events is an important parameter in that organism's response to subsequent stress. This finding is in close agreement with the work of Seligman and his associates using canine Ss. Weiss (1968) has reported related findings: albino rats which could perform a "coping" response to escape or avoid electric shock developed less severe physiological sysmptoms of stress than yoked Ss which received the same shocks in an inescapable fashion. Weiss has also provided an excellent discussion of the relation of the above-cited results to the results obtained in "executive" monkey experiments.

The present findings suggest that an effect similar to Seligman's learned helplessness phenomenon is not restricted to canine Ss, but is general enough to be observed in the rather emotional A strain of mice. It is most interesting that the effect occurs even when quite dissimilar stressors (electric shock vs water) are employed, and when rather dissimilar responses (jumping vs swimming) are involved.

A detailed analysis of the physiological changes produced by the various shock treatments would be necessary before it could be said with certainty whether the inferior water-escape performance of the inescapable shock animals was due to a "learning" process or, rather, was the result of a more basic physiological mechanism. For example, the two shock treatments may have produced differential stress (Selye, 1950). Possible differential changes in body heat regulation (Goodell, Graham, \& Wolff, 1950) could have produced differential susceptibility to the water temperature of the second task, and it is known that water temperature is an important determinant of swimming performance in mice (Werboff, Haggett, \& Anderson, 1967).

\section{REFERENCES}

GOODELL, H., GRAHAM, D. T., \& WOLFF, H. Changes in body heat regulation associated with varying life situations and emotional states. In Life stress and bodily disease. Proceedings for the Association for Research in Nervous and Mental Diseases. Vol. 29. Baltimore: Williams \& Wilkins, 1950. Pp. 418-431.

OVERMIER, J. B., \& SELIGMAN, M. E. Effects of inescapable shock upon subsequent escape and avoidance responding. Journal of Comparative \& Physiological Psychology, 1967, 63, 28-33.

SELIGMAN, M. E., \& MAIER, S. F. Failure to escape traumatic shock. Journal of Experimental Psychology, 1967, 74, 1-9.

SELYE, H. Stress: The physiology and pathology of exposure to stress. Montreal: Acta, 1950.

WEISS, J. M. Effects of coping responses on stress. Journal of Comparative \& Physiological Psychology, 1968, 65, 251-260.

WERBOFF, J., HAGGETT, B. N., \& ANDERSON, A. Swimming performance of mice: Time to submersion as a function of water temperature. Physiology \& Behavior, 1967, 2, 39-43. 